\title{
Forum
}

\section{Biodiversity monitoring in developing countries: what are we trying to achieve?}

\author{
Finn Danielsen, Marlynn M. Mendoza, Phillip Alviola, Danilo S. Balete, Martin Enghoff, Michael K. Poulsen and \\ Arne E. Jensen
}

In a stimulating review of biodiversity monitoring programmes, Yoccoz et al. (2001) recently concluded that many existing programmes suffer from two major design deficiencies: a lack of well-articulated objectives, and a neglect of different sources of error in the estimation of biological diversity. The paper was primarily devoted to the sources of data uncertainty. While we agree with the conclusion that substantial thought should be given to the question of design, and to 'how', 'what' and 'why' to monitor, it is worth considering what we want to achieve by monitoring and, considering the socioeconomic context, what is practically feasible. Design deficiencies that apply in developed countries may be irrelevant in some developing countries where the de facto day-to-day management of biological resources is largely in the hands of poor rural people (Getz et al., 1999), and local authorities have virtually no operational funding.

Our main aim here is to highlight the fact that, in many parts of the world, the context is different from the baseline of Yoccoz et al. (2001). More importantly (and not discussed by Yoccoz et al., who primarily reviewed initiatives in the USA), most biodiversity monitoring programmes in less wealthy countries suffer from being unrealistically large, complicated and impossible to sustain with the locally available funds and human resources (Danida, 2000). Many programmes collapse almost immediately when the donor funding stops because they are designed at a cost-level that will never be sustained. In addition, most programmes are unable to contribute to biodiversity conservation because they

Finn Danielsen (Corresponding author) Martin Enghoff, Michael K. Poulsen and Arne E. Jensen Nordic Agency for Development and Ecology, Skindergade 23, DK-1159 Copenhagen, Denmark. E-mail: fd@nordeco.dk

Marlynn M. Mendoza Protected Areas and Wildlife Bureau, Ninoy Aquino Parks and Wildlife Center, North Avenue, Diliman, Quezon City, Metro Manila, 1100 Philippines.

Phillip Alviola University of the Philippines, Los Baños, Laguna, Philippines.

Danilo S. Balete Laksambuhay Conservation, Inc., 10241 Mt. Bulusan St, U-2, Umali Subd., Los Banos, Laguna, Philippines.

Received 6 August 2002. Revision requested 4 March 2003. Accepted 18 June 2003 are ineffective in integrating information into decisionmaking. These constraints are particularly acute at a time when there is an urgent need to increase the effectiveness of conservation efforts in the tropics (Achard et al., 2002).

One could argue that these constraints are unrelated to biodiversity monitoring and should be addressed by strengthening the government institutions responsible and providing additional training and funds (Bawa \& Menon, 1997). However, whether we like it or not, we are not likely to see significantly improved environmental departments in developing countries for some time. By neglecting these constraints and emphasizing the need for more standardized approaches, the recommendations of Yoccoz et al. (2001) may lead to repeated attempts to develop unrealistic programmes that only divert scarce funds from fundamental management priorities (e.g. Sheil, 2001). It is time to recognize the inherent tensions between data standardization, facility of collection and ease of making contributions to management. What really matters for management-oriented biodiversity monitoring in developing countries is that methods are very simple, cost-effective and possible to sustain with limited external support, and that the time from data sampling to management action is short (Danida, 2000). Recent advances in combining scientific and participatory methods may provide a solution (Margoluis \& Salafsky, 1998; World Bank, 1998; Danielsen et al., 2000; ETFRN, 2002).

In the Philippines at least 156 management actions have been undertaken in eight protected areas over $2 \frac{1}{2}$ years on the basis of integrated scientific and participatory monitoring methods (Nordeco \& DENR, 2002). In relation to the hunting of wildlife, actions included: the development of bylaws at tribal (lapat), village and municipal level, seasonal closures for hunting, banning of certain destructive hunting methods, the establishment of a system of fines for leaving snares unattended, awarenessraising about needs for hunting regulations among local people, strengthened enforcement of hunting regulations in certain areas, and pilot-testing of more sustainable hunting practices.

Similar initiatives that combine methods from the natural and social sciences have been developed in Laos (Ling, 2000; Steinmetz, 2000), Yunnan in China (Rijsoort \& Jinfeng, 2002) and Tanzania (Danida, 2003). 
Examples of methods are provided in Table 1. An added advantage, beyond the simplicity and low cost, is that the meaning of the monitoring can be grasped by local people who are in practice the custodians of the areas. In fact the methods are focused on authorities supporting local people in enhancement and formalization of the existing, informal monitoring already carried out.

Central to the success of integrated assessment methods in these initiatives are: (i) that representatives of local communities are involved in developing the local application of the methods, (ii) that already existing communitybased monitoring systems are recognized and built upon, (iii) that focus is at the field/village level where management decisions are taken, (iv) that monitoring activities are kept simple and fitted into the day-to-day work of the local people, (v) that government staff are involved, and (vi) that there is mutual trust between local communities and government staff.

The strength of this approach does not lie in detecting trends with a statistically acceptable degree of confidence or in contributing to international publishing. It lies instead in proven efficiency, even in the short-term, in strengthening local management of the land and resources and dealing with threats to biodiversity (ETFRN, 2002; Nordeco \& DENR, 2002). Moreover, it makes local stakeholders more motivated to agree on and participate in law enforcement, resource use regulation and reaction to encroachment by outsiders, increasing the likelihood of successful management. In addition, this approach improves communication between local stakeholders and authorities, increases transparency of decision-making and strengthens community-based resource management systems.

How general are these considerations? It seems that integrating scientific and participatory biodiversity monitoring techniques have particular potential in areas where (i) authorities embark on shared management of resources with local people, and authorities and locals have common interest in the management objectives, (ii) rural people depend on the use of natural resources and have a relative strong societal coherence and long history of settlement, and (iii) the resources are not so valuable that they attract powerful outsiders against whom local people have no defence (Danielsen et al., 2000; ETFRN, 2002). While this approach has thus far been used primarily in protected areas, it is likely to be equally effective in other places where the appropriate authorities have interests and staff.

The main drawback of this approach is that we do not yet know the extent to which the method is able to detect true trends. By its very nature, the integrated approach does not include all of the desirable elements to ensure that monitoring programs provide unequivocal answers (Margules et al., 1998). In-depth monitoring of selected habitats and species are also vital. Most programmes integrating scientific and participatory biodiversity monitoring methods in developing countries are relatively young and untested. Although cost-effective, it remains to be seen whether they will be sustained in the long term. A key determinant is whether conservation professionals and scientists will accept that this approach has potential for improving resource management.

Many countries are moving towards decentralization of natural resource management. International policy agreements emphasize the need for increased public participation in environmental decision-making (e.g. the Aarhus Convention of 1998 (UNECE, 1998) on access to information, public participation in decision-making, and access to justice in environmental matters). Integrating participatory methods into biodiversity assessment can be a powerful tool for implementing these policies.

Countries party to the Convention on Biological Diversity are obliged to monitor biodiversity (Article 7.b) but many have yet to establish monitoring programmes (Global Forest Coalition/FERN, 2002). If significant financial support for monitoring is to be provided by

Table 1 Examples of field methods for monitoring biodiversity and resource use.

\begin{tabular}{|c|c|c|}
\hline Type of method & Field method & Source \\
\hline \multirow[t]{4}{*}{ Conventional scientific methods } & Permanent forest inventory plots & Alder \& Synnott, 1992 \\
\hline & Territory mapping of birds & Bibby et al., 2000 \\
\hline & Arthropod protocols & Coddington et al., 1991 \\
\hline & $\begin{array}{l}\text { Quantitative socio-economic survey with statistical } \\
\text { analysis }\end{array}$ & Marsh, 1999 \\
\hline \multirow[t]{4}{*}{ Integrated scientific and participatory methods } & $\begin{array}{l}\text { Focus group discussions between protected area } \\
\text { staff and local volunteer members of 'community } \\
\text { monitoring groups' }\end{array}$ & Danielsen et al., 2000 \\
\hline & $\begin{array}{l}\text { Routine observation of wildlife and resource use } \\
\text { during regular patrols }\end{array}$ & Danielsen et al., 2000 \\
\hline & Recording by community members of observations of & Steinmetz, 2000 \\
\hline & key species and visits of outsiders in a village logbook & Ling, 2000 \\
\hline
\end{tabular}


governments and development agencies it will be essential that the programmes make a real contribution to arresting the root causes of extinction. Otherwise, biodiversity monitoring programmes in developing countries are likely to remain no more than isolated academic exercises.

\section{References}

Achard, F., Eva, H.D., Stibig, H.-J., Mayaux, P., Gallego, J., Richards, T. \& Malingreau, J.-P. (2002) Determination of Deforestation Rates of the World's Humid Tropical Forests. Science, 297, 999-1002.

Alder, D. \& Synnott, T.J. (1992) Permanent sample plot techniques for mixed tropical forest. Tropical Forestry Papers, 25.

Bawa, K.S. \& Menon, S. (1997) Biodiversity monitoring: the missing ingredients. Trends in Ecology \& Evolution, 12, 42.

Bibby, C.J., Burgess, N.D. \& Hill, D.A. (2000) Bird Census Techniques. Academic Press, London, UK.

Coddington, J.A., Griswold, C.E., Dávila, D.S., Peñaranda, E. \& Larcher, S.F. (1991) Designing and testing sampling protocols to estimate biodiversity in tropical ecosystems. In The Unity of Evolutionary Biology: Proceedings of the Fourth International Congress of Systematic and Evolutionary Biology (ed. E.C. Dudley), pp. 44-60. Dioscorides Press, Portland, USA.

Danida (2000) Towards 'Best' Practice in Biodiversity Conservation in Southern Africa. Royal Danish Ministry of Foreign Affairs, Copenhagen, Denmark.

Danida (2003) Development of Biodiversity Monitoring for Udzungwa Mountains Forest Management and Biodiversity Conservation Project and Community Based Natural Woodlands Management Project (MEMA). Final Report. Royal Danish Ministry of Foreign Affairs, Copenhagen, Denmark.

Danielsen, F., Balete, D.S., Poulsen, M.K., Enghoff, M., Nozawa, C.M. \& Jensen, A.E. (2000) A simple system for monitoring biodiversity in protected areas of a developing country. Biodiversity and Conservation, 9, 1671-1705.

European Tropical Forest Research Network (ETFRN) (2002) Participatory Monitoring and Evaluation of Biodiversity: Internet Workshop and Policy Seminar. Environmental Change Institute, University of Oxford, Oxford, UK [http://www.etfrn.org/etfrn/workshop/biodiversity/ index.html, accessed 23 July 2003].

Getz, W.M., Fortmann, L., Cumming, D., du Toit, J., Hilty, J., Martin, R., Murphree, M., Owen-Smith, N., Starfield, A.M. \& Westphal, M.I. (1999) Sustaining Natural and Human Capital: Villagers and Scientists. Science, 283, 1855-1856.
Global Forest Coalition/FERN (2002) Status of Implementation of Forest-Related Clauses in the CBD: An Independent Review \& Recommendations for Action. Global Forest Coalition [http://www.fern.org/pubs/reports/cbd/finalcbd.pdf, accessed 23 July 2003].

Ling, S. (2000) NBCA Biodiversity Monitoring. Part One: Monitoring Manual. Part Two: Trainers Notes. Forest Management and Conservation Programme, Lao-Finnish-World Bank-GEF Cooperation, Vientiane, Lao PDR.

Margoluis, R. \& Salafsky, N. (1998) Measures of Success: A Systematic Approach to Designing, Managing and Monitoring Community-Oriented Conservation Projects. Biodiversity Support Program Adaptive Management Series, Washington, DC, USA.

Margules, C.R., Austin, M.P., Davies, K.F., Meyers, J.A. \& Nicholls, A.O. (1998) The design of programs to monitor forest biodiversity: lessons from the Wog Wog habitat fragmentation experiment. In Forest Biodiversity Research, Monitoring and Modelling: Conceptual Background and Old World Case Studies (eds. F. Dallmeier \& J.A. Comiskey), pp. 183-196. Parthenon Publishing, Paris, France.

Marsh, I. (ed.) (1999) Sociology: Dealing with Data. Longman, Essex, UK.

Nordeco \& DENR (2002) DENR Biodiversity Monitoring System. Implementation Results from Eight Protected Areas January 1999-June 2001, The Philippines. Department of Environment and Natural Resources, Manila, prepared for the World Bank.

Rijsoort, J. van \& Jinfeng, Z. (2002) Development of Participatory Resources Monitoring in Two Nature Reserves in Yunnan, P.R. China [http://www.etfrn.org/etfrn/workshop/ biodiversity/index.html, accessed 23 July 2003].

Sheil, D. (2001) Conservation and biodiversity monitoring in the tropics: realities, priorities and distractions. Conservation Biology, 15, 1179-1182.

Steinmetz, R. (2000) Ecological Surveys, Monitoring and the Involvement of Local People in Protected Areas of Lao PDR. IIED Evaluating Eden Series, IIED, London, UK.

United Nations Economic Commission for Europe (UNECE), Environment and Human Settlements Division (1998) Aarhus Convention (Convention on Access to Information, Public Participation in Decision-making and Access to Justice in Environmental Matters), adopted 25 June 1998 [http:/ / www.unece.org/env/pp, accessed 23 July 2003].

World Bank (1998) Guidelines for Monitoring and Evaluation for Biodiversity Projects. Environment Department Note No. 65, the World Bank, Washington, DC, USA.

Yoccoz, N.G., Nichols, J.D. \& Boulinier, T. (2001) Monitoring of biological diversity in space and time. Trends in Ecology \& Evolution, 16, 446-453. 